\title{
Therapeutic effects of Crocin in autoimmune diseases: a review
}

\author{
Shahla Korani, ${ }^{1}$ Mitra Korani, ${ }^{2}$ Thozhukat Sathyapalan, ${ }^{3}$ Amirhossein Sahebkar ${ }^{4,5,6 *}$ \\ ${ }^{1}$ Research Center of Oils and Fats, Kermanshah University of Medical Sciences, \\ Kermanshah, Iran \\ ${ }^{2}$ Nanotechnology Research Center, Buali (Avicenna) Research Center, Mashhad University of \\ Medical Science, Mashhad, Iran \\ ${ }^{3}$ Department of Academic Diabetes, Endocrinology and Metabolism, Hull York Medical \\ School, University of Hull, Hull HU3 2JZ, UK \\ ${ }^{4}$ Neurogenic Inflammation Research Center, Mashhad University of Medical Sciences, \\ Mashhad, Iran \\ ${ }^{5}$ Biotechnology Research Center, Pharmaceutical Technology Institute, Mashhad University \\ of Medical Sciences, Mashhad 9177948564, Iran \\ ${ }^{6}$ School of Pharmacy, Mashhad University of Medical Sciences, Mashhad, Iran
}

\section{*Corresponding authors:}

Amirhossein Sahebkar, PharmD, PhD, Department of Medical Biotechnology, School of Medicine, Mashhad University of Medical Sciences, Mashhad, Iran, P.O. Box: 91779-48564, Iran. Tel: 985118002288; Fax: 985118002287; E-mail: sahebkara@mums.ac.ir; amir saheb2000@yahoo.com

Running title: Corcin in autoimmune diseases 


\begin{abstract}
The immune system when acts against self-molecules results in an imbalance in immunologic tolerance leading to the development of several autoimmune diseases such as rheumatoid arthritis, asthma, ulcerative colitis, type 1 diabetes and multiple sclerosis. Improved recognition of the mechanisms of autoimmune diseases has led to the advancement of the management of these diseases. The principal mediators of autoimmune diseases are inflammatory molecules. The herbal medicines due to their anti-oxidant and anti-inflammatory properties have an important role in the management of autoimmune diseases. Crocin is the principal chemical component extracted from saffron which is a medicinal plant. This review focuses on the therapeutic effects of Crocin in various autoimmune diseases.
\end{abstract}

Keywords: Crocin; Autoimmune diseases; anti-oxidant; inflammation; Saffron. 


\section{Introduction}

The immune system consists of cellular and soluble protein components that protect our body against various infections and cancers by identifying and neutralizing infectious agents or cancer cells. When the immune system leads to a hyperactive immune response against foreign molecules and the body's cells and proteins the result can be severe. The reaction against selfmolecules resulting in infiltrations of the inflammatory cells and tissue destruction can cause one of the various forms of autoimmune diseases. Autoimmune diseases (ADs) are a group of chronic disease with relatively high prevalence in young people and have a significant impact on health care costs. ADs vary significantly in the susceptible organs they impact and in their clinical symptoms and signs with some being restricted to specific tissues. In some cases, the immune response is precise to a specific cell type [e.g. oligodendrocytes in multiple sclerosis (MS) or pancreatic $\beta$ cells in type 1 diabetes (T1DM)], but it will be able to target a wider range of cells and tissues $(1,2)$. Like many other complex disorders, genetic and environmental factors play an important role in the development of ADs. Polymorphisms in different genes result in reduced threshold or faulty regulation for $\mathrm{T}$ cells and B cells activation. Besides, environmental agents can induce the activation of self-reactive cells that can get out of control and are reacts against self-antigens(2).

One of the phenomena associated with autoimmune diseases is efferocytosis. This phenomenon involves removing the remains of apoptosis cells by phagocytic cells. If the efferocytosis is impaired the apoptotic remnants of cells can trigger auto-immune responses such as systemic lupus erythematosus (SLE) or rheumatoid arthritis (RA). One of the factors that can impair the efferocytosis phenomenon is the impairment of innate immunity receptors such as C1q which plays an important role in phagocytosis. When the efferocytosis is impaired, the remains of 
apoptotic cells can act as the auto-antigen for the immune system and can cause self-acting responses to these antigens as seen in various autoimmune diseases (3-5).

Cytokines are one of the key factors in the initiation and regulation of immune responses. The cytokine network is known as one of the most complex and precise biological networks in the immune system that directly or indirectly impacts a wide range of immune and non-immune cells. It is clear that if a cytokine network is impaired, the result can be a variety of spectrum of immune disorders, including autoimmune diseases. The classic immune response includes Th1, Th2 and Th17, each of which has its specific cytokines and functions. Th1 responses were centered on interferon-gamma (IFN- $\gamma$ ) and interleukin-12 (IL-12) cytokines which trigger cellular immune responses. While Th2 and Th17 responses result in allergic responses based on IL-4, IL-5 and IL-13, and neutrophil rich responses based on IL-17, respectively. Most autoimmune diseases have been identified by an impaired balance between Th1, Th2 and Th17 responses. On the other side, the cytokine network can trigger or suppress immune responses. Immune suppressive cytokines include IL-10, TGF- $\beta$ and their main role is suppression of immune responses. Changes in the balance of inflammatory cytokines such as IFN- $\gamma$, IL-2 and IL-12 and immunosuppressive cytokines can be one of the main reasons for not adequately suppressing the immune system against auto-antigens leading to various autoimmune disorders (6-8).

The use of natural products is recognized as a helpful strategy for the management of various diseases from ancient to the present time due to their low toxicity and relatively strong efficacy. There is growing evidence that herbals have numerous therapeutic impacts in different disorders such as cancers, neurodegenerative diseases and diabetes.

Saffron (Crocus sativus L.) Stigmas contain secondary metabolites such as anthocyanins, flavonoids, terpenes and carotenoids. Crocin and crocetin are the two main carotenoids of saffron. Numerous studies on the pharmacological effects of Crocin have confirmed 4

This is the peer reviewed version of the following article: Korani, S, Korani, M, Sathyapalan, T, Sahebkar, A. Therapeutic effects of Crocin in autoimmune diseases: A review. BioFactors. 2019; 1-9., which has been published in final form at https://doi.org/10.1002/biof.1557. This article may be used for non-commercial purposes in accordance with Wiley Terms and Conditions for Use of Self-Archived Versions. 
antidepressant (9), anti-atherosclerotic (10), anti-platelet aggregation (11), renoprotective (12), anti-tumor $(13)$ and anti-oxidant $(14,15)$ properties. Crocin has also been reported to have protective effects against gentamicin-induced nephrotoxicity (16). Crocin represses microglial activation and reduces the inflammation-induced neurotoxicity in rats (10).In this review, we assess the applications of Crocin for the management of ADs.

\section{Crocin}

Saffron (Crocus sativus L.) belongs to a monocotyledon species of the Iridaceae family (17). Saffron is cultivated in many areas of the world such as Iran, India, Greece, Spain, Turkey, Italy, Azerbaijan and China (18). Saffron is the most important part of the stigma and includes various secondary metabolites such as flavonoids, terpenes, carotenoids and anthocyanins. Chemical analysis has identified Crocin, picroCrocin, crocetin and safranal as the most bioactive compounds of saffron. The main metabolites of saffron are carotenoids and are responsible for the color and taste of the spice (19). The quality of the saffron used as a food coloring and flavouring agent or as a medicinal herb is mainly based on four bioactive components which are safranal, picroCrocin, crocetin and Crocin. They are responsible for its odor, bitter taste and intense red color (20). Crocin (hydrosoluble) is obtained from the esterification of crocetin with sugars and form crystals with a melting point of $186^{\circ} \mathrm{C}$. It forms $6 \%-16 \%$ of the dry stigmas $(21,22)$. There are five types of -Crocin (Figure 1$)$. Most of the Crocins except Crocin-1 are found in cis-trans isomeric forms (23). Crocins have a glycoside carotenoid structure and include trans-crocetin diester of gentiobiose, trans-crocetin ester of glucose-gentiobiose, trans-crocetin ester of gentiobiose, a cis-crocetin diester of gentiobiose, trans-crocetin diester of glucose and cis-crocetin ester of glucose-gentiobiose $(18,19)$. Masi et al. studied the properties of twenty-five different types of Crocins from Italy and Iran and they reported the total dry mass concentration of Crocin ranged between 302 to $548 \mathrm{mg} / \mathrm{g}$, which was dependent on the geographical origin of the Crocin (24). 
There is a growing interest in the isolated components of saffron on human health due to their high anti-oxidant ability and potent anti-inflammatory effects by following mechanisms: lipid peroxidation reduction, diazinon (DZN) inhibition, inflammatory cytokines and neuronal damage markers reductions due to its free radical scavenging activity. (25).

\section{Anti-oxidant and anti-inflammatory properties of Crocin}

Reactive oxygen species (ROS) are the products of cellular metabolism which can change redox balance. Alterations in intracellular redox can affect various cell functions since most of the stress response systems and apoptotic signaling pathways are susceptible to redox environment (26).

In a DPPH (2,2-diphenyl-1- picrylhydrazyl) free radical scavenging to investigate the effect of safranal and Crocin showed that these compounds can donate an $\mathrm{H}$ atom to the DPPH radical. Safranal and Crocin displayed a high free radical scavenging activity, 34\% and 50\% for 500 ppm solution in methanol, respectively. Studies have proven that Crocin at the concentration of $500 \mathrm{lM}$ could meaningfully reduce ROS production following either 24 and 48 hours treatment of the myeloma cell line U266B1 in the presence of Crocin. The cellular damage produced by ROS has been associated with many disorders such as cancer and neurodegenerative disorders. Therefore anti-oxidants' mechanisms discovery is a key role in the management of oxidative stress-related disorders (13).

Crocin scavenges free radicals (e.g. superoxide anions) and so could potentially have a protective role for cells against oxidative stress. Crocin is suitable for sperm cryopreservation and in protecting hepatocytes from toxins. Because of its potent anti-oxidant property, it could be suitable in the therapy of neurodegenerative disorders(27). Alterations in the enzyme activity and the level of translation in the cellular redox system such as glutathione peroxidase (GPx), glutathione S-transferase (GST), catalase and superoxide dismutase (SOD) are shown as potential mechanisms. Saffron extracts have different mechanisms of action such as 6

This is the peer reviewed version of the following article: Korani, S, Korani, M, Sathyapalan, T, Sahebkar, A. Therapeutic effects of Crocin in autoimmune diseases: A review. BioFactors. 2019; 1-9., which has been published in final form at https://doi.org/10.1002/biof.1557. This article may be used for non-commercial purposes in accordance with Wiley Terms and Conditions for Use of Self-Archived Versions. 
affecting signaling pathways of free radicals in the monocytes, interaction with enzymes (peroxidases) and inhibition of ROS during interaction of a varied range of proteins with antioxidant compounds (28).

Crocin can significantly reduce the size of brain ischemia, decrease malondialdehyde (MDA) level and increase GPx and SOD activities. MDA has been known as a biomarker of oxidative stress (29). The endoplasmic cell (ER) is closely related to the oxidative stress of the cell; changes in the level of mRNA expression of the ER stressors including BiP, XBP-1/s, CHOP and PERK are associated with many stress-related illnesses such as autoimmune diseases and cancer. Crocin is considered as an inhibitor of stress by inducing ER by mRNA expression of these genes as well as ER stress inhibition by reduction of malondialdehyde and nitric oxide (NO) in disorders of the neuronal cells (30). Liver damages caused by oxidative xenobiotic drugs can be potentially reversed by Crocin treatment. Studies have shown that Crocin-treated rats show a higher $\mathrm{SH}$ level than their controls groups in a dose-dependent manner which suggests that Crocin helps to refill of the total thiol pool(31).

The anti-inflammatory effects of saffron are based on its anti-oxidant and free radical scavenging properties that appear to be related to crocetin and Crocin. All inflammatory disorders are associated with a release of ROS species with proinflammatory molecules produced and transported to all tissues. For instance, the system of monocytes and macrophages, together with the endothelial cells and platelets regulates both intrinsic immune responses and inflammatory responses by delivering cytokines and ROS in cardiovascular diseases. The natural amounts of the most important free radical scavengers, glutathione Stransferase (GST), glutathione reduction (GSH), glutathione reductase-dependent NADPH (G.red-NADPH), glutathione peroxidase (GSHPx), catalase ( CAT) and superoxide dismutase (SOD) are reduced in most of the diseases related to immune system (Figure 2) (32). 


\section{Treatment of autoimmune diseases}

ADs are a heterogeneous group of disorders that involve susceptible organs (33) whose incidence is increasing worldwide. In this study effects of Crocin on ADs such as rheumatoid arthritis, type 1 diabetes, ulcerative colitis and multiple sclerosis are reviewed. Crocin was suggested as a candidate herbal medicine for preventing and treating ADs (Table1).

\section{Rheumatoid arthritis (RA)}

RA is a chronic systemic autoimmune disease characterized by the inflammation of the synovial membranes and destruction of articular cartilages (34). Around 1-2\% of the population worldwide is affected by RA which carries significant morbidity and mortality. RA is common among women in comparison to men. The age of incidence is around 40-60 years of age. Juvenile cases of RA are also reported (35). The exact pathogenesis of RA is still largely unknown.

Studies show that proinflammatory cytokines are responsible for initiating several inflammatory and autoimmune diseases. Cytokines (e.g. TNF- $\alpha$, IL-1 $\beta$ ) play a key role in the development of RA(36). Several herbal medicines and their isolated components including Crocin are used in the management of arthritis with the fewer side-effects(37). Animal models of RA are used to evaluate the impact of anti-arthritic medications and for investigating the pathogenesis of the disease (38).

Crocin therapy significantly reduced the RA symptoms in rats including reduced paw inflammation arthritis, reduced chondrocyte death, joint inflammation, paw swelling, reduced arthritis score, bone and cartilage destruction in a dose-dependent method. Also, Crocin administration reduced the serum levels of MMPs (MP-1, MMP-3, MMP-13) and proinflammatory cytokines (TNF-a, IL-6, CXCL8 and IL-17) in a dose-dependent manner(39). 
Li et al. studied the effects of Crocin on arthritis in the human fibroblast-like synoviocytes (FLS) and CIA in mice. They found that Crocin treatment significantly reduced the expression of TNF- $\alpha$, IL-1 $\beta$ and IL-6 in human FLS induced by LPS. In vivo studies showed that plasma concentrations of IL-1 $\beta$, IL-6 and TNF- $\alpha$ were reduced in Crocin-treated CIA group compared to the control group. Authors studied the effects of Crocin $(500 \mu \mathrm{M})$ on NF- $\kappa B$ signaling in FLS and observed that these cells showed lower amounts of p-IкB $\alpha$ caused by LPS, p65 and p-IкB kinase (IKK) $\alpha / \beta$ comparative to the untreated cells. Besides, they showed that Crocin treatment significantly reduced plasma amounts of IL-1 $\beta$, IL-6 and TNF- $\alpha$ in CIA mice. Therefore, their study proved that Crocin can inhibit the production of IL-1 $\beta$, IL-6 and TNF- $\alpha$ by inhibiting the NF- $\kappa \mathrm{B}$ activation via its interaction with IKK (40).

Hemshekhar et al studied the antiarthritic effects of Crocin. They found that Crocin efficiently neutralized the increased serum amounts of enzymatic (MMP-3, MMP-9, MMP-13 and hyaluronidases) and non-enzymatic (IL-1b, COX-2, PGE2, NF-kB, IL-6, TNF-a, and ROS) inflammatory mediators. Also, they found that Crocin improves the anti-oxidant status of the system (CAT, GSH, GST and SOD). It protected the bone erosion by suppressing the increased levels of bone joint cathepsin-D, exoglycosidases and tartrate-resistant acid phosphatases (41).

\section{Ulcerative colitis (UC)}

UC is a chronic inflammatory disorder and its incidence is increasing worldwide (42). UC results in mucosal inflammation starting from the rectum and extending to proximal segments of the colon (43). UC is characterized by interchanging periods of intense inflammation and long periods of remission in the colon (44). Kawabata et al studied the effects of Crocin in the inhibition of colitis-associated colon carcinogenesis in mice. They showed that dietary Crocin inhibited the progression of chemically-induced colonic adenocarcinomas. It suppressed the immunohistochemical expression and proliferation of $\mathrm{NF}-\kappa \mathrm{B}$ as well as increased the 9

This is the peer reviewed version of the following article: Korani, S, Korani, M, Sathyapalan, T, Sahebkar, A. Therapeutic effects of Crocin in autoimmune diseases: A review. BioFactors. 2019; 1-9., which has been published in final form at https://doi.org/10.1002/biof.1557. This article may be used for non-commercial purposes in accordance with Wiley Terms and Conditions for Use of Self-Archived Versions. 
expression of the Nrf2 gene in adenocarcinoma cells. On the other hand, dietary Crocin inhibited dextran sodium sulphate (DSS) -induced colitis and reduced the expression of inflammatory cytokines genes (TNF- $\alpha, \mathrm{NF}-\kappa \mathrm{B}, \mathrm{IL}-1 \beta$, IL-6, IFN- $\gamma, \mathrm{COX}-2$ ) and inducible expression iNOS gene(45). Khodir AE et al studied the anti-ulcerogenic and the coloprotective effects of Crocin against experimentally-induced UC in the rat. Crocin and felodipine were administrated for eight days. The results showed that Crocin had significant protective effect against experimentally-induced colonic damage in rats as well as anti-ulcerogenic and coloprotective effects. Moreover, Crocin significantly inhibited inflammatory, oxidant and apoptotic signaling pathways in the rat by increasing colon anti-oxidant defenses (Nrf2, Heme Oxygenase- 1 signaling). It also reduced colon TNF- $\alpha$ and $\mathrm{Ca}+2$ contents with down-regulation of caspase-3 expression. These results demonstrated that Crocin has anti-inflammatory, antioxidant and antiapoptotic properties resulting in anti-ulcerogenic and coloprotective effects (46). Rezaei et al. investigated the therapeutic effects of Crocin against chemically induced colitis in mice. They showed that Crocin treatment reduced colitis symptoms in mice including diarrhea, body weight loss, colon shortening and rectal bleeding. Histology of colon tissues showed that Crocin effectively reduced colon histopathological score through inhibiting antiinflammatory responses in chemically-induced colitis mice. These studies demonstrate the potential therapeutic effect of Crocin against colitis (47).

\section{Type 1 diabetes (T1DM)}

T1DM is a chronic inflammatory disease where autoreactive T-cells and monocytic cells infiltrate into pancreatic islets destroying insulin-producing $\beta$ cells causing hyperglycemia (48) Hyperglycemia induces ROS production which results in an imbalance between the production of ROS and anti-oxidant defensive mechanisms causing oxidative stress (49). In diabetes, the 
free radicals cause damage to many organic substrates such as proteins, carbohydrates nucleic acids and lipids of the host cells resulting in various diabetes complications. ROS affects the $\beta$-cells as a result of activating the transcription factor NF- $\kappa \beta$ in the macrophages (50).

Altinoz et al. demonstrated the impact of Crocin in the management of cardiovascular complications by reducing oxidative stress in diabetic rats. Crocin reduced malondialdehyde (MDA) and significantly increased GSH levels in both cardiac tissues and in serum. Besides, Crocin improved hyperlipidemia showing that Crocin might prevent diabetes-induced cardiovascular complications by reduction of both oxidative stress and dyslipidemia (51). Administration of Crocin in diabetic rats resulted in a significant reduction of total oxidant level, restored sperm characteristics and testicular damage suggesting that Crocin improves most of the reproductive complications of DM (52). Crocin inhibited pro-inflammatory cytokines (TNF- $\alpha$, IL-6) in the diabetic rats suggesting a therapeutic potential of Crocin in the management of diabetes complications (53).

\section{Multiple sclerosis (MS)}

MS disease is a chronic autoimmune, inflammatory demyelinating disorder of the central nervous system (CNS) and can occur in young adulthood (54). The exact etiology of MS remains unclear, however, it could be multifactorial including both genetic and environmental factors (55). In MS, T-cells and macrophage infiltrations ddestroy myelin sheath in the CNS which weakens the transmission of nerve impulses. Two key properties of this disease are acute inflammation and demyelination that is accompanied by neuronal degeneration and secondary axonal damage(54). Syncytin-1 is a protein activating the pro-inflammatory pathways and autoimmune cascades. Syncytin-1 is related to the neuroinflammation as well as oligodendrocyte death and is highly expressed in astrocytes, glial cell and microglia of MS lesions (56). Saffron has been shown to have a protective effect in autoimmune encephalomyelitis (EAE) mice via inhibition of leukocyte infiltration and oxidative stress 
suggesting Crocin could be of therapeutic potential in the management of MS. It was shown that EAE increases the transcript levels of the ER stress genes XBP-1/s. Administration of Crocin on day 7 post-EAE induction inhibited ER stress and inflammatory gene expression in the spinal cord as well as reduced the expression of ER stress genes XBP-1/s (57). Crocin has a neuroprotective effect in vitro against oligodendrocyte cytotoxicity, NO-induced astrocyte and syncytin-1, respectively. Besides, Crocin administration on day seven post-EAE induction inhibited inflammatory gene expression and ER stress in the spinal cord and decreased neuropathology in EAE with less neurological damage. These results demonstrate the roles of ER stress and Syncytin-1 in the pathophysiology of MS and that Crocin could be a potential therapeutic agent (58).

Studies have shown that saffron has anti-neuroinflammatory and antidepressant effects in MS as well as Crocin has antidepressant effects in mild to moderate depression. Therefore, saffron can be favourably effective in depressive complaints of MS patients (57).

\section{Molecular mechanism of anti-oxidant activity of Crocin:}

Crocin modifies various molecular mechanisms in cells to perform anti-oxidant activities. One of the main activities by Crocin is a change in the expression of genes related in the redox system of cells such as glutathione S-transferase (GST), glutathione peroxidase (GPx), catalase and superoxide dismutase (SOD). In addition to changes in gene expression levels, interactions with cellular enzymes including SOD proteins or peroxidase have also been reported to induce the anti-oxidant activity of Crocin $(10,13,28,59)$. Another mechanism underlying the antioxidant activity of Crocin is the alteration of the stress marker genes in the reticuloendothelial cell (ER) system. Genes related to ER oxidative stress markers, whose expression is modulated by the Crocin are XBP-1/s, BiP, PERK and CHOP $(13,30)$. Finally, changes in the epigenetics and changes in telomerase activity by Crocin are also indicative of the ability of Crocin to change at the molecular level of cells and induce anti-oxidant effects of Crocin $(60,61)$. 


\section{Conclusion}

Several studies have shown that Crocin is an active component of saffron and could be used for the management of various inflammatory diseases. Crocin has shown to have an antioxidant, anti-inflammatory and antiapoptotic effect. It has been reported that saffron can modulate NF- $\mathrm{BB}$ and MAPK pathways and can control the expression of genes encoding the inflammatory cytokines (e.g. IL-1, IL-2, IL-6, TNF- $\alpha$ ), adhesion molecules (e. g., ICAM, VCAM, E-selectin), inducible enzymes (such as., COX- 2 and iNOS), chemokines and many of the acute phase proteins, all of which play key roles in regulating inflammatory processes in the immune system (62). It is believed that excess oxidative stress plays a key role in the pathogenesis of ADs by increasing inflammatory mediators, unbalancing the immunological tolerance and inducing apoptotic cell death. Evidence shows that Crocin could have a therapeutic role in the management of various autoimmune inflammatory diseases such as rheumatoid arthritis, T1DM, ulcerative colitis and multiple sclerosis (Table1). More research needs to be done on the effects of Crocin in the treatment of other ADs and also clinical studies investigating the effects of Crocin. Finally, Crocin modifies various molecular mechanisms in cells to perform anti-oxidant activities such as changing in the expression of genes related in the redox system of cells, alteration of the stress marker genes in the ER system and changes in the epigenetics and telomerase activity of cells.

Conflict of interests: None.

Funding: None. 
This is the peer reviewed version of the following article: Korani, S, Korani, M, Sathyapalan, T, Sahebkar, A. Therapeutic effects of Crocin in autoimmune diseases: A review. BioFactors. 2019; 1-9., which has been published in final form at https://doi.org/10.1002/biof.1557. This article may be used for non-commercial purposes in accordance with Wiley Terms and Conditions for Use of Self-Archived Versions. 


\section{References}

1. Lettre G, Rioux JD. Autoimmune diseases: insights from genome-wide association studies. Human molecular genetics. 2008;17(R2):R116-R21.

2. Rosenblum MD, Remedios KA, Abbas AK. Mechanisms of human autoimmunity. The Journal of clinical investigation. 2015;125(6):2228-33.

3. Gheibi Hayat SM, Bianconi V, Pirro M, Sahebkar A. Efferocytosis: molecular mechanisms and pathophysiological perspectives. Immunology and cell biology. 2019;97(2):124-33.

4. Pirro M, Barreto GE, Sahebkar A. The role of efferocytosis in autoimmune diseases. Frontiers in immunology. 2018;9:1645.

5. Botto M, Walport MJ. C1q, autoimmunity and apoptosis. Immunobiology. 2002;205(45):395-406.

6. Teymouri M, Pirro M, Fallarino F, Gargaro M, Sahebkar A. IL-35, a hallmark of immuneregulation in cancer progression, chronic infections and inflammatory diseases. International journal of cancer. 2018;143(9):2105-15.

7. Wang R-X, Yu C-R, Dambuza IM, Mahdi RM, Dolinska MB, Sergeev YV, et al. Interleukin-35 induces regulatory $B$ cells that suppress autoimmune disease. Nature medicine. 2014;20(6):633.

8. $\quad$ Ringkowski S, Loke J, Huang S, Ahmadzai H, Herth FJ, Thomas PS, et al. Enhanced LPSinduced activation of IL-27 signalling in sarcoidosis. Respiratory medicine. 2016;117:243-53.

9. Jam IN, Sahebkar AH, Eslami S, Mokhber N, Nosrati M, Khademi M, et al. The effects of crocin on the symptoms of depression in subjects with metabolic syndrome. Advances in Clinical and Experimental Medicine. 2017;26(6):925-30.

10. Nam KN, Park Y-M, Jung H-J, Lee JY, Min BD, Park S-U, et al. Anti-inflammatory effects of crocin and crocetin in rat brain microglial cells. European journal of pharmacology. 2010;648(13):110-6.

11. Xi L, Qian Z, Du P, Fu J. Pharmacokinetic properties of crocin (crocetin digentiobiose ester) following oral administration in rats. Phytomedicine. 2007;14(9):633-6.

12. Yaribeygi H, Mohammadi MT, Rezaee R, Sahebkar A. Crocin improves renal function by declining Nox-4, IL-18, and p53 expression levels in an experimental model of diabetic nephropathy. Journal of Cellular Biochemistry. 2018;119(7):6080-93.

13. Hoshyar R, Mollaei H. A comprehensive review on anticancer mechanisms of the main carotenoid of saffron, crocin. Journal of Pharmacy and Pharmacology. 2017;69(11):1419-27.

14. Nikbakht-Jam I, Khademi M, Nosrati M, Eslami S, Foroutan-Tanha M, Sahebkar A, et al. Effect of crocin extracted from saffron on pro-oxidant-anti-oxidant balance in subjects with metabolic syndrome: A randomized, placebo-controlled clinical trial. European Journal of Integrative Medicine. 2015;8(3):307-12.

15. Yaribeygi $\mathrm{H}$, Mohammadi MT, Sahebkar A. Crocin potentiates antioxidant defense system and improves oxidative damage in liver tissue in diabetic rats. Biomedicine and Pharmacotherapy. 2018;98:333-7.

16. Yarijani ZM, Najafi H, Madani SH. Protective effect of crocin on gentamicin-induced nephrotoxicity in rats. Iranian journal of basic medical sciences. 2016;19(3):337.

17. Bhat J, Broker R. Riboflavine and thiamine contents of saffron, Crocus sativus linn. Nature. 1953;172(4377):544.

18. Javadi B, Sahebkar A, Emami SA. A survey on saffron in major Islamic traditional medicine books. Iranian journal of basic medical sciences. 2013;16(1):1.

19. Gismondi A, Serio M, Canuti L, Canini A. Biochemical, antioxidant and antineoplastic properties of Italian saffron (Crocus sativus L.). American Journal of Plant Sciences. 2012;3(11):1573. 20. Srivastava R, Ahmed H, Dixit R. Crocus sativus L.: a comprehensive review. Pharmacognosy reviews. 2010;4(8):200. 
21. Bolhasani A, Bathaie S, Yavari I, Moosavi-Movahedi A, Ghaffari M. Separation and purification of some components of Iranian saffron. Asian Journal of Chemistry. 2005;17(2):725.

22. Singla RK, Bhat G. Crocin: an overview. Indo Global Journal of Pharmaceutical Sciences. 2011;1(4):281-6.

23. ALONSO GL, SALINAS MR, GARIJO J, SÁNCHEZ-FERNÁNDEZ MA. Composition of crocins and picrocrocin from Spanish saffron (Crocus sativus L.). Journal of Food Quality. 2001;24(3):219-33.

24. Masi E, Taiti C, Heimler D, Vignolini P, Romani A, Mancuso S. PTR-TOF-MS and HPLC analysis in the characterization of saffron (Crocus sativus L.) from Italy and Iran. Food chemistry. 2016;192:75-81.

25. Moallem SA, Hariri AT, Mahmoudi M, Hosseinzadeh H. Effect of aqueous extract of Crocus sativus L.(saffron) stigma against subacute effect of diazinon on specific biomarkers in rats. Toxicology and industrial health. 2014;30(2):141-6.

26. Chiu J, Dawes IW. Redox control of cell proliferation. Trends in cell biology. 2012;22(11):592601.

27. Ebadi M. Pharmacodynamic basis of herbal medicine: CRC press; 2010.

28. Mostafavinia SE, Khorashadizadeh M, Hoshyar R. Antiproliferative and proapoptotic effects of crocin combined with hyperthermia on human breast cancer cells. DNA and cell biology. 2016;35(7):340-7.

29. Abdullaev F, Espinosa-Aguirre J. Biomedical properties of saffron and its potential use in cancer therapy and chemoprevention trials. Cancer Detection and prevention. 2004;28(6):426-32.

30. Zheng $\mathrm{Y}-\mathrm{Q}$, Liu J-X, Wang J-N, Xu L. Effects of crocin on reperfusion-induced oxidative/nitrative injury to cerebral microvessels after global cerebral ischemia. Brain research. 2007;1138:86-94.

31. Soszyński M, Bartosz G. Decrease in accessible thiols as an index of oxidative damage to membrane proteins. Free Radical Biology and Medicine. 1997;23(3):463-9.

32. Poma A, Fontecchio G, Carlucci G, Chichiricco G. Anti-inflammatory properties of drugs from saffron crocus. Anti-Inflammatory \& Anti-Allergy Agents in Medicinal Chemistry (Formerly Current Medicinal Chemistry-Anti-Inflammatory and Anti-Allergy Agents). 2012;11(1):37-51.

33. Fierabracci A, Milillo A, Locatelli F, Fruci D. The putative role of endoplasmic reticulum aminopeptidases in autoimmunity: insights from genomic-wide association studies. Autoimmunity reviews. 2012;12(2):281-8.

34. Nakken B, Papp G, Bosnes V, Zeher M, Nagy G, Szodoray P. Biomarkers for rheumatoid arthritis: From molecular processes to diagnostic applications-current concepts and future perspectives. Immunology letters. 2017;189:13-8.

35. Li X, Jiang C, Zhu W. Crocin reduces the inflammation response in rheumatoid arthritis. Bioscience, biotechnology, and biochemistry. 2017;81(5):891-8.

36. Rathore B, Mahdi F, Mahdi AA, Das SK. CROCUS SATIVUS AND NYCTANTHES ARBORTRISTIS EXTRACT MODULATES ANTI-INFLAMMATORY CYTOKINE IN EXPERIMENTAL ARTHRITIS. International Journal of Pharmaceutical Sciences and Research. 2017;8(2):768.

37. MARWA N. EMAM aRNAE-L. Therapeutic Effect of Crocin in Collagen Induced Rheumatoid Arthritis Rat Model (Crocin in Rheumatoid Arthritis). MEDICAL JOURNAL CAIRO UNIVERSITY. 2017;85(1):1-10.

38. Bendele A. Animal models of rheumatoid arthritis. J Musculoskelet Neuronal Interact. 2001;1(4):377-85.

39. Liu W, Sun Y, Cheng Z, Guo Y, Liu P, Wen Y. Crocin exerts anti-inflammatory and anti-arthritic effects on type II collagen-induced arthritis in rats. Pharmaceutical biology. 2018;56(1):209-16.

40. Li L, Zhang H, Jin S, Liu C. Effects of crocin on inflammatory activities in human fibroblast-like synoviocytes and collagen-induced arthritis in mice. Immunologic research. 2018;66(3):406-13.

41. Hemshekhar M, Santhosh MS, Sunitha K, Thushara R, Kemparaju K, Rangappa K, et al. A dietary colorant crocin mitigates arthritis and associated secondary complications by modulating

This is the peer reviewed version of the following article: Korani, S, Korani, M, Sathyapalan, T, Sahebkar, A. Therapeutic effects of Crocin in autoimmune diseases: A review. BioFactors. 2019; 1-9., which has been published in final form at https://doi.org/10.1002/biof.1557. This article may be used for non-commercial purposes in accordance with Wiley Terms and Conditions for Use of Self-Archived Versions. 
cartilage deteriorating enzymes, inflammatory mediators and antioxidant status. Biochimie. 2012;94(12):2723-33.

42. Xiao B, Zhang Z, Viennois E, Kang $Y$, Zhang M, Han MK, et al. Combination therapy for ulcerative colitis: orally targeted nanoparticles prevent mucosal damage and relieve inflammation. Theranostics. 2016;6(12):2250.

43. Dignass A, Eliakim R, Magro F, Maaser C, Chowers Y, Geboes K, et al. Second European evidence-based consensus on the diagnosis and management of ulcerative colitis part 1: definitions and diagnosis. Journal of Crohn's and Colitis. 2012;6(10):965-90.

44. Melo MNd, Soares LAL, Porto CRdC, Araújo AAd, Almeida MdG, Souza TPd, et al. Spray-dried extract of $P$ hyllanthus niruri $L$. reduces mucosal damage in rats with intestinal inflammation. Journal of Pharmacy and Pharmacology. 2015;67(8):1107-18.

45. Kawabata K, Tung NH, Shoyama Y, Sugie S, Mori T, Tanaka T. Dietary crocin inhibits colitis and colitis-associated colorectal carcinogenesis in male ICR mice. Evidence-Based Complementary and Alternative Medicine. 2012;2012.

46. Khodir AE, Said E, Atif H, ElKashef HA, Salem HA. Targeting Nrf2/HO-1 signaling by crocin: Role in attenuation of AA-induced ulcerative colitis in rats. Biomedicine \& Pharmacotherapy. 2019;110:389-99.

47. Rezaei N, Avan A, Pashirzad M, Rahmani F, Moradi Marjaneh R, Behnam-Rassouli R, et al. Crocin as a novel therapeutic agent against colitis. Drug and chemical toxicology. 2019:1-8.

48. Clark M, Kroger CJ, Tisch RM. Type 1 diabetes: a chronic anti-self-inflammatory response. Frontiers in immunology. 2017;8:1898.

49. Poljsak B, Šuput D, Milisav I. Achieving the balance between ROS and antioxidants: when to use the synthetic antioxidants. Oxidative medicine and cellular longevity. 2013;2013.

50. Hoarau E, Chandra V, Rustin P, Scharfmann R, Duvillie B. Pro-oxidant/antioxidant balance controls pancreatic $\beta$-cell differentiation through the ERK1/2 pathway. Cell death \& disease. 2014;5(10):e1487.

51. Altinoz E, Taskin E, Oner Z, Elbe H, Arslan BA. The effect of saffron (its active constituent, crocin) on the cardiovascular complication and dyslipidemia in streptozotocin induced diabetic rats. African Journal of Traditional, Complementary and Alternative Medicines. 2015;12(5):1-7.

52. Sefidgar SM, Ahmadi-hamedani M, Jebelli Javan A, Narenji Sani R. Effect of crocin on biochemical parameters, oxidative/antioxidative profiles, sperm characteristics and testicular histopathology in streptozotocin-induced diabetic rats. Avicenna Journal of Phytomedicine. 2019.

53. Samarghandian S, Azimi-Nezhad M, Farkhondeh T. Crocin attenuate Tumor Necrosis Factoralpha (TNF- $\alpha$ ) and interleukin-6 (IL-6) in streptozotocin-induced diabetic rat aorta. Cytokine. 2016;88:20-8.

54. Mojaverrostami S, Bojnordi MN, Ghasemi-Kasman M, Ebrahimzadeh MA, Hamidabadi HG. A Review of Herbal Therapy in Multiple Sclerosis. Advanced pharmaceutical bulletin. 2018;8(4):575.

55. Hasan KM, Walimuni IS, Abid H, Datta S, Wolinsky JS, Narayana PA. Human brain atlas-based multimodal MRI analysis of volumetry, diffusimetry, relaxometry and lesion distribution in multiple sclerosis patients and healthy adult controls: implications for understanding the pathogenesis of multiple sclerosis and consolidation of quantitative MRI results in MS. Journal of the neurological sciences. 2012;313(1-2):99-109.

56. Wang X, Huang J, Zhu F. Human Endogenous Retroviral Envelope Protein Syncytin-1 and Inflammatory Abnormalities in Neuropsychological Diseases. Frontiers in psychiatry. 2018;9.

57. Ghazavi A, Mosayebi G, Salehi H, Abtahi H. Effect of ethanol extract of saffron (Crocus sativus L.) on the inhibition of experimental autoimmune encephalomyelitis in C57bl/6 mice. Pakistan journal of biological sciences: PJBS. 2009;12(9):690-5.

58. Deslauriers AM, Afkhami-Goli A, Paul AM, Bhat RK, Acharjee S, Ellestad KK, et al. Neuroinflammation and endoplasmic reticulum stress are coregulated by crocin to prevent demyelination and neurodegeneration. The Journal of Immunology. 2011;187(9):4788-99.

This is the peer reviewed version of the following article: Korani, S, Korani, M, Sathyapalan, T, Sahebkar, A. Therapeutic effects of Crocin in autoimmune diseases: A review. BioFactors. 2019; 1-9., which has been published in final form at https://doi.org/10.1002/biof.1557. This article may be used for non-commercial purposes in accordance with Wiley Terms and Conditions for Use of Self-Archived Versions. 
59. Ashrafi M, Bathaie SZ, Abroun S, Azizian M. Effect of crocin on cell cycle regulators in Nnitroso-N-methylurea-induced breast cancer in rats. DNA and cell biology. 2015;34(11):684-91.

60. Hoshyar R, Bathaie SZ. 98 The impact of active metabolites obtained from saffron on H1Oligonucleotide interaction. Journal of Biomolecular Structure and Dynamics. 2013;31(sup1):62-. 61. Hoshyar R, Bathaie SZ, Kyani A, Mousavi MF. Is there any interaction between telomeric DNA structures, G-quadruplex and I-motif, with saffron active metabolites? Nucleosides, Nucleotides and Nucleic Acids. 2012;31(11):801-12.

62. Zeinali M, Zirak MR, Rezaee SA, Karimi G, Hosseinzadeh H. Immunoregulatory and antiinflammatory properties of Crocus sativus (Saffron) and its main active constituents: A review. Iranian Journal of Basic Medical Sciences. 2019;22(4):334.

63. Bathaie SZ, Farajzade A, Hoshyar R. A review of the chemistry and uses of crocins and crocetin, the carotenoid natural dyes in saffron, with particular emphasis on applications as colorants including their use as biological stains. Biotechnic \& Histochemistry. 2014;89(6):401-11.

\section{Figure legends}

Figure 1: Types of chemical structures of Crocin (63).

Figure 2: The effects of Crocin on autoimmune diseases. 
This is the peer reviewed version of the following article: Korani, S, Korani, M, Sathyapalan, T, Sahebkar, A. Therapeutic effects of Crocin in autoimmune diseases: A review. BioFactors. 2019; 1-9., which has been published in final form at https://doi.org/10.1002/biof.1557. This article may be used for non-commercial purposes in accordance with Wiley Terms and Conditions for Use of Self-Archived Versions. 


\begin{tabular}{|c|c|c|c|c|}
\hline $\begin{array}{l}\text { Autoimmune } \\
\text { disease }\end{array}$ & Dose crocin & $\begin{array}{l}\text { Experimental } \\
\text { model /cell type }\end{array}$ & Effects & Authers \\
\hline $\begin{array}{l}\text { Type II } \\
\text { collagen- } \\
\text { induced } \\
\text { arthritis }\end{array}$ & 10,20 or $40 \mathrm{mg} / \mathrm{kg}$ & Rats & $\begin{array}{l}\text { inhibit the expression of } \\
\text { TNF- } \alpha, \text { IL-17, IL-6, CXCL8 } \\
\text { expression levels of MMP- } \\
1,-3 \text { and }-13\end{array}$ & Liu W et al(39) \\
\hline $\begin{array}{l}\text { Adjuvant- } \\
\text { induced } \\
\text { arthritis }\end{array}$ & $\begin{array}{l}6.25,12.5,25 \\
\mathrm{mg} / \mathrm{kg}\end{array}$ & Sprague Dawley rats & $\begin{array}{l}\text { reduced the iNOS } \\
\text { production / TNF- } \alpha, \mathrm{IL}-1 \beta \text {, } \\
\text { IL- } 6\end{array}$ & Li X et al(35) \\
\hline $\begin{array}{l}\text { collagen- } \\
\text { induced } \\
\text { arthritis }\end{array}$ & $\begin{array}{l}50 \mathrm{mg} / \mathrm{kg} \text {, } \\
\text { intraperitoneal } \\
\text { injection, once } \\
\text { daily for } 1 \text { week }\end{array}$ & mice & $\begin{array}{l}\text { blocking NF-KB signalling } \\
\text { reduced production TNF- } \alpha \text {, } \\
\text { IL-1 } \beta \text {, IL- } 6\end{array}$ & Li l et al(40) \\
\hline $\begin{array}{l}\text { Adjuvant- } \\
\text { induced } \\
\text { arthritis }\end{array}$ & $10,20 \mathrm{mg} / \mathrm{kg}$ & Wistar rats & $\begin{array}{l}\text { neutralize MMP-13, MMP- } \\
3 \text { and MMP-9 and HAases } \\
\text { /TNF- } \alpha, \text { IL-1b, NF-kB, IL-6, } \\
\text { COX-2, PGE2 and ROS } \\
\text { inhibit exoglycosidases, } \\
\text { cathepsin-D and tartrate } \\
\text { resistant acid phosphatases } \\
\text { quenche ROS, lipid } \\
\text { peroxides }\end{array}$ & $\begin{array}{c}\text { Hemshekhar M } \\
\text { et al(41) }\end{array}$ \\
\hline $\begin{array}{l}\text { Ulcerative } \\
\text { Colitis }\end{array}$ & $\begin{array}{c}0,50,100,200 \\
\text { ppm }\end{array}$ & ICR Mice & $\begin{array}{l}\text { decrease TNF- } \alpha, \mathrm{IL}-1 \beta, \mathrm{IL}-6 \text {, } \\
\text { IFN } \gamma, \mathrm{NF}-\mathrm{kB}, \mathrm{COX}-2 \text { and } \\
\text { inducible NO synthase in } \\
\text { the colorectal and increase } \\
\text { Nrf2 }\end{array}$ & $\begin{array}{c}\text { Kawabata et } \\
\text { al(45) }\end{array}$ \\
\hline $\begin{array}{l}\text { Ulcerative } \\
\text { colitis }\end{array}$ & $20 \mathrm{mg} / \mathrm{kg}$ & Sprague Dawley rats & $\begin{array}{l}\text { Enhance colon anti-oxidant } \\
\text { defences and reduce colon } \\
\text { TNF- } \alpha, \mathrm{Ca}+2 \text { contents, } \\
\text { enhance Nrf2, HO-1 } \\
\text { activity, reduce CASP3 } \\
\text { activity }\end{array}$ & $\begin{array}{l}\text { Khodir AE et } \\
\text { al(46) }\end{array}$ \\
\hline $\begin{array}{l}\text { Ulcerative } \\
\text { colitis }\end{array}$ & $\begin{array}{l}\text { 50-ppm or 200- } \\
\text { ppm }\end{array}$ & C57BL/6 mice & $\begin{array}{l}\text { attenuates body weight } \\
\text { loss, diarrhoea, rectal } \\
\text { bleeding, colon shortening }\end{array}$ & $\begin{array}{l}\text { Rezaei N et } \\
\quad \text { al(47) }\end{array}$ \\
\hline $\begin{array}{l}\text { Streptozotocin- } \\
\text { induced } \\
\text { diabetic rats }\end{array}$ & $20 \mathrm{mg} / \mathrm{kg}$ & Wistar rats & $\begin{array}{l}\text { decrease s MDA, total } \\
\text { cholesterol, TG, VLDL, } \\
\text { increases GSH in serum }\end{array}$ & $\begin{array}{l}\text { Altinoz E et } \\
\text { al(51) }\end{array}$ \\
\hline $\begin{array}{l}\text { Streptozotocin- } \\
\text { induced } \\
\text { diabetic rats }\end{array}$ & $40,60 \mathrm{mg} / \mathrm{kg}$ & Wistar rats & $\begin{array}{l}\text { decreases blood glucose, } \\
\text { cholesterol, TG, LDL, TOS, } \\
\text { OSI }\end{array}$ & $\begin{array}{c}\text { Sefidgar SM et } \\
\text { al(52) }\end{array}$ \\
\hline
\end{tabular}
effects of Crocin in autoimmune diseases: A review. BioFactors. 2019; 1-9., which has been published in final form at https://doi.org/10.1002/biof.1557. This article may be used for non-commercial purposes in accordance with Wiley Terms and Conditions for Use of Self-Archived Versions. 


\begin{tabular}{|l|l|l|l|l|}
\hline & & & & \\
\hline $\begin{array}{l}\text { Streptozotocin- } \\
\text { induced } \\
\text { diabetic rats }\end{array}$ & $10,20,30 \mathrm{mg} / \mathrm{kg}$ & Wistar rats & $\begin{array}{l}\text { decreases MDA, NO, total } \\
\text { lipids, T G, cholesterol } \\
\text { levels increase GSH, } \\
\text { catalase, SODs activities, } \\
\text { inhibits the expression of } \\
\text { TNF } \alpha \text {-IL-6 }\end{array}$ & $\begin{array}{c}\text { Samarghandian } \\
\text { S et al(53) }\end{array}$ \\
\hline EAE model & $\begin{array}{c}100 \mu \mathrm{L} \text { saffron } \\
\text { extract }\end{array}$ & C57BL/6 mice & $\begin{array}{l}\text { Inhibits oxidative } \\
\text { stress/leukocyte infiltration }\end{array}$ & $\begin{array}{c}\text { Ghazavi A et } \\
\text { al(57) }\end{array}$ \\
\hline $\begin{array}{l}\text { In vitro } \\
\text { (human fetal } \\
\text { astrocytes) } \\
\text { In vivo (C57BL/6 } \\
\text { wild and CHOP2/2 } \\
\text { mice) }\end{array}$ & $200 \mathrm{mM}$ & inhibits Syncytin-1 & $\begin{array}{c}\text { Deslauriers AM } \\
\text { et al(58) }\end{array}$ \\
\hline
\end{tabular}
effects of Crocin in autoimmune diseases: A review. BioFactors. 2019; 1-9., which has been published in final form at https://doi.org/10.1002/biof.1557. This article may be used for non-commercial purposes in accordance with Wiley Terms and Conditions for Use of Self-Archived Versions. 
Table 1: Effects of Crocin on autoimmune diseases.

TNFa:Tumor necrosis factor alpha,IL17: Interleukin 17,IL6: Interleukin 6, CXCL8: Chemokine (C-X-C motif) ligand 8, MMP:Matrix metallopeptidase, iNOS: Inducible nitric oxide synthase, IL1 $\beta$ : Interleukin 1, NF-KB :nuclear factor kappa-light-chain-enhancer of activated B cells, HAases: hyaluronidases, COX-2: Cyclooxygenase-2, PGE2: Prostaglandin E2, ROS: Reactive oxygen species, LPO: Lipid peroxidation, MDA: Malondialdehyde, GSH :glutathione reduction, CAT: catalase, IFNY: Interferon gamma, NO synthases: Nitric oxide synthases, Nrf2: Nuclear factor erythroid 2-related factor 2, HO-1: Heme Oxygenase-1, CASP3:Caspase-3, TG: Triglyceride, VLDL: Very-low-density lipoprotein , GSH Glutathione, LDL:Low-density lipoprotein , TOS:Total oxidant stress, OSI:Oxidative stress index, NO: Nitric oxide, SODs:superoxide dismutases 